\title{
Effect of Socio-Economic Variables on Fish Production of Small Farmers in Tocantins State, Brazil
}

\author{
Roberto Manolio Valladão Flores and Manoel Xavier Pedroza Filho \\ Embrapa Fisheries and Aquaculture, Palmas 77020-020, Brazil
}

Received: October 30, 2013 / Published: April 20, 2014.

\begin{abstract}
Fish farming is a strategic activity for both the economy and food security of the Tocantins state. Nowadays, there are about eighty small fish farmers in the region of Divinópolis in Tocantins state. The technological level of fish farmers is low and it was found that only $30 \%$ of farmers could ever get to the point of selling fish. Therefore, the objective of this paper is to investigate which socioeconomic factors have influence on the fact of fish farmers in the region of Divinópolis and in Tocantins state reach a level of efficiency in production enough that the fish can be good for sale in the local market. To estimate this relation the logit model was chosen, with methodology based on the empirical model used in Musaba and Namukwambi. Following the production of fish farms in the Western of Tocantins state, the collect of the data, during 2012, were conduct with interviews of 30 fish farms, visiting them in their homes and applying a questionnaire. Through the use of econometric models of probability for limited dependent variables, it was found that factors such as participation in federal programs to transfer income, total area of water and production in ponds are key factors in determining the likelihood of producer to sell fish.
\end{abstract}

Key words: Aquaculture, small fish farming, logit, Tocantins state.

\section{Introduction}

In the Tocantins state, fish farming is one of the agricultural activities of highest potential, presenting a considerable growth in recent years and exceeding the value of capture fishery sector. Between 2000 and 2009, the aquaculture production in Tocantins grew $445 \%$, from $1,102 \mathrm{t}$ to $6,004 \mathrm{t}$ (Fig. 1). This value is currently $79 \%$ of total fish production (farming and capture) in the state. Fish farming is a strategic sector for the economy and for food security of the state. Apart from being an important source of employment and income, fish farming can also play a role of considerable importance in the environment.

Familiar fish farming stands out for its strong social and economic appeal, because of its potential of food security, income generation and diversification of rural establishments. In this context, it is important to

Corresponding author: Roberto Manolio Valladão Flores, master, researcher, research field: economics statistics. E-mail: roberto.valladao@embrapa.br. note that the Tocantins state has significant shortcomings in social and economic development. According to Brazilian Institute for Geography and Statistics (IBGE), the GDP per capita of Tocantins state (base year 2008) is $\mathrm{R} \$ 10,223.15$ and it corresponds to $36 \%$ less than the average of Brazil [1]. The state's HDI is 0.75 (2005), which puts him in the 15th position compared to the other Brazilian states [2]. About food security, Tocantins state is the Brazilian state with the second largest food insecurity, with $52 \%$ of its population suffering from food shortage permanent or temporary [3].

Considering these facts, in 2008, the Ministry of Fisheries and Aquaculture (MPA), in partnership with the regional office of rural tins (state rural extension institute), initiated a project aimed to promote the development of family farming in Divinópolis region, located in Western state of Tocantins. About 20 fish farmers began activity and the project consisted in the distribution of fingerlings and technical assistance. 


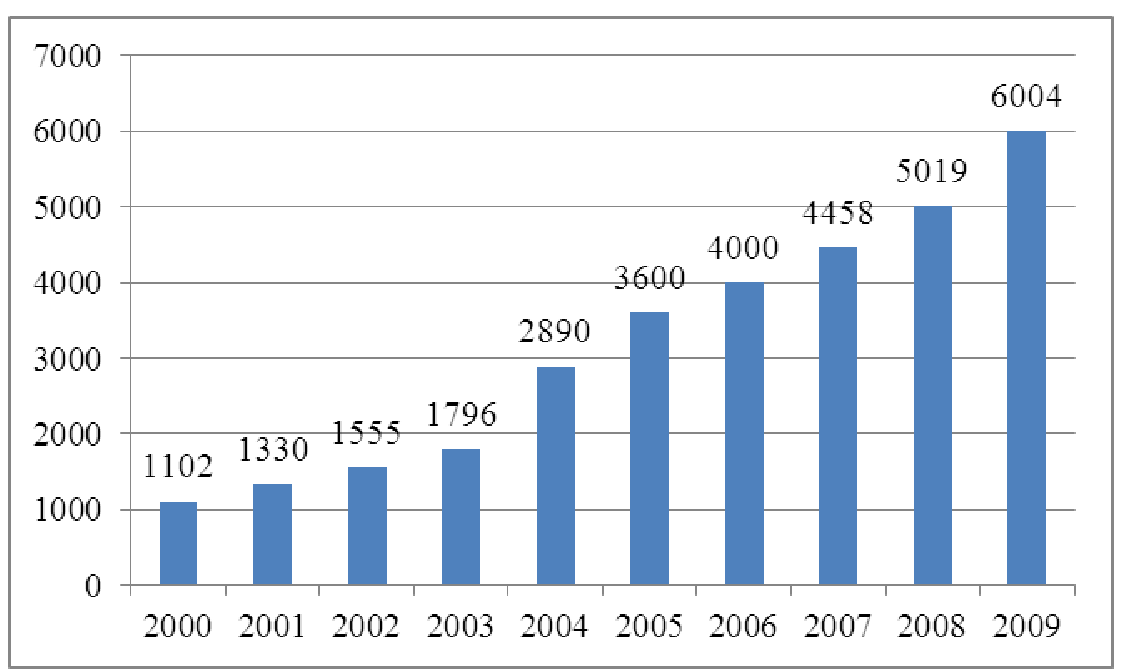

Fig. 1 Production of fish farm in Tocantins ( $t$ ).

Source: IBAMA/MPA.

With an estimated population of 6,300, Divinópolis has the second largest source of economic, trailing only the services [4]. The city has 592 farms, in which 443 are considered as family farming. However, even though majority in number of units, family farming establishments are a minority in area, totaling only $17 \%$ of the agricultural area of the municipality, with about 30,000 ha.

Nowadays, there are about 80 familiar fish farmers in the Divinópolis region, with the most of them entering in the activity on its own initiative, encouraged by the experience of the first producers. The enthusiasm of producers regarding fish farming is an indicator of the rapid growth in activity. Fish farming is basically developed autonomously or in small groups, especially in relation to the acquisition of inputs (feed, fingerlings, etc.). Despite the growing membership of farmer fish activity, there are not any specific associative representation related to fish farming in these municipalities.

The production structure is formed mainly by small ponds dug and small dams. The water uptake is mainly carried out by rain water, without technical guidance. The main species produced are tambaqui, caranha, piabanha, piau, pintado and tambacu.

These details are result of a research project being developed by Embrapa Fisheries and Aquaculture in the region, called Divinópolis Project, whose goal is to diagnose the major production bottlenecks and propose further actions of research and extension. There is already relevant information enabling improved knowledge of farmers. It is known, for example, that most fish farmers in the region have monthly income below $\mathrm{R} \$ 2,000.00$ and that half of them have only income derived from agriculture.

It is also known that the technological level of the fish farmers is low, with the occurrence of problems related to fish mortality, poor water quality and poor feed management. These facts highlight the need for technological improvements. Another factor to consider is the lack of information necessary to technically support legalization of fish farmer activity, which results in the informality of a large number of producers. All these factors, besides little experience in the activity, may contribute to growth of fish farming cluttered and unsustainable.

Thus, although there are about 80 fish producers in the region, most of them do not produce efficiently, failing to make the fish gain weight and size sufficient to attract buyers of the product. So fish produced by these farmers is destined only domestic consumption by the family. Thus, it is necessary to understand what factors cause some producers to be unable to reach a more qualified production to sell their fish. 
Farmers have key characteristics that can explain this fact. Factors such as women's participation in fish production, number of members living in the farm, religion and time of experience in the activity have a considerable degree of variation between this population and it is important to understand what their relationship is with the quality of fish produced.

The objective of this paper is to investigate which socioeconomic factors have an influence on the fact of fish farmers in the region of the Divinópolis in Tocantins state reach a level of efficiency in production enough that the fish can be good for sale in the local market.

\section{Bibliographic Review}

Family farming is a form of productive arrangement that can leverage significantly, food production and income generation in Brazil. However, more than 70 million people still live in conditions of food insecurity [5]. Broaden the spectrum of marketable products, ensuring the consumption, presents itself as an option for survival and better income for farmers [6]. Edínia and Borges [7] indicated that the greatest challenge of family farming is to adapt and organize their production from the technology available, because when it is well used has been viable.

In this way, the aquaculture, even being considered a recent activity in Brazil, can be adapted to small scale in order to utilize the resources available on the farm and increase the nutritional quality of the diet family [8]. Due to its high productivity and the final product is a high protein food, fish farming stands out as an activity to be experienced by family farms and can significantly contribute to increasing food security [9]. Several studies have demonstrated the feasibility of fish farming in generating income and nutritional quality of food eaten [10]. At the same time, the activity can generate negative social impacts when conducted without harmony with the traditional communities [11].

About economics in fish farming, surveys have shown that small-scale fish activities are feasible. An example is the production of tilapia in fish cages that presents a profitability rate of $22.57 \%$ for a production cycle of 180 days in the city of IlhaSolteira-SP [12]. Another example is the integrated agriculture-aquaculture which substantially increased protein intake and reduced the rate of poverty among small farmers in Malawi, Africa [13].

Some authors have also investigated the influence of socioeconomic factors in aquaculture and fish production chain. Caffey and Kazmierczak [14] used a multinomial logit model to analyze the impact of various socioeconomic characteristics of aquaculture producers in the state of Louisiana on the adoption of new technologies to the industry. It was found that the adoption of technologies can increase if there are more educational programs focused on exclusive commitment of time working in aquaculture and business managed by the family residing on the property.

Using similar methodology, Musaba and Namukwambi [15] evaluated the socioeconomic determinants of fish consumption in Windhoek in Namibia. Through interviews with 120 vendors were considered characteristics such as age, gender, education, family size, marital status and income. The authors found that income, education and family size have significant effect on the probability of selling products such as hake.

Thus, considering the importance that aquaculture and family farms are gaining in Brazil and Tocantins and the results that studies are finding on the effects of socioeconomic variables, it is clearly important assessing what the effects of these variables on the sale of fish of small farmers for the suggested region.

\section{Methodology}

\subsection{The Model}

To estimate the effects of different socioeconomic factors on the probability of the small farmer sell, the fish can be used by a qualitative choice model, such as 
probit or logit, where the dependent variable is binary. As the probit and logit models have very close results of which are difficult to distinguish statistically [16, 17], the logit model was chosen to perform the estimates proposed in this paper. The methodology is based on the empirical model used in Musaba and Namukwambi [15].

Thus, the logit model for a representative fish farmer $i$ can be expressed as follows:

$$
P_{i}=1 /\left(1+e^{-Z_{i}}\right)
$$

where, $e$ is the base of natural logarithm, $Z_{i}$ is an index determined by an independent variable, $X_{i}$ and $P_{i}$ is the probability that the farmer fish will make a certain choice. Eq. (1) is estimated as:

$$
\log \left(P_{i} /\left(1-P_{i}\right)\right)=Z_{i}=\beta_{0}+\beta_{j} X_{i j}+u_{i}
$$

The expression on the left side of Eq. (2) is the logarithm of the probability of representative individual sell fish to the odds of non-selling. $u_{i}$ is the error term. The parameter $\beta_{j}$ is estimated by the logit model by maximum likelihood.

The estimates of coefficients $j$ generated by logit model do not have a useful measure of explanation between dependent variables and independent variables except for the sign and significance of these coefficients. Given this, the change in the probability of selling the fish with respect to a unit change in the explanatory variable was estimated as:

$$
\Delta P_{i}=\beta_{k} P_{i}\left(1-P_{i}\right)
$$

where, $P_{i}$ is the probability of a farmer sells fish evaluated at the mean and $\beta_{k}$ is the estimated coefficient of the " $k$-th variable". The change in probability $\left(\Delta P_{i}\right)$ is a function of probability, and when multiplied by 100 , gives the percentage change in the probability of an occurring event given a change in the variable, all things being constant.

\subsection{Specification of Model}

The dependent variable was binary with an assigned value of 1 when the farmer sells fish, at some point since it began to produce, and equal to zero if he has never sold fish to any customer. In this way, the logit model used to investigate the effect of socioeconomic variables on this dependent variable can be specified as:

$$
\begin{aligned}
& P(Z)=\beta_{0}+\beta_{1} \exp +\beta_{2 \text { members }}+\beta_{3} \text { fem } \\
& +\beta_{4 \text { transf }}+\beta_{5 \text { relig }}+\beta_{6} \text { income }+\beta_{7} \text { pond } \\
& +\beta_{8} \text { byprod }+\beta_{9} \text { area }+\varepsilon
\end{aligned}
$$

where, the dependent variable is a discrete variable as already defined above and $\varepsilon$ is the error term of the model. The independent variables are socioeconomic factors as defined:

"exp" corresponds to the time of experience in the aquaculture activity of the responsible for production. It is expected that as more experience has the farmer, better is the quality of activity, and thus more likely to be able to sell the fish.

"members" corresponds to the total of family members residing in the farm. Fish farmers that participated in the survey are all from small farms and have many productive activities on the property. Fish farming in general is not the most lucrative and requires a reasonable time of dedication to the management. Thus, a family with more member residents has more people for the cultivation of fish and, consequently, should increase the likelihood of success in sales.

"fem" is a dummy variable that takes the value 1 when there is female participation in the cultivation of fish or when just the woman is responsible for the production. The variable is zero when only men work on the fish farming. Women tend to be more careful in their activities, which helps to the higher quality. Then, the expected sign for this variable is positive.

"transf" is a dummy variable that takes the value 1 if the household participates in a program of government transfer income, as the BolsaFamília and Bolsa Verde, for example. It is expected the positive sign for this variable since these programs guarantee a minimum 
income for families, which help with the costs of purchasing necessary inputs for fish farming.

"relig" is also a dummy variable and controls the effects of religion practiced by each family. Among families participating in the survey, only two religions were observed, Catholic and Protestant. The variable has the value one when the family is protestant and zero when is Catholic. As religion has influence in the routine of family members, it is important to have its effect controlled in the model.

"income" is a continuous variable representing the average monthly family income in reais (Brazilian currency). This variable can have two different effects on the dependent variable. Firstly, households with higher income have greater resources to invest in fish farming, which would increase the likelihood of selling fish. At the same time, higher income means more activities on the farm besides fish, leaving the fish with less time dedicated and resulting in a lower probability of sale.

"pond" is a dummy variable that has value 1 if production occurs in ponds dug. The variable is zero if production occurs in dams. Thus, this variable represents two different production systems. It is expected that production in ponds increase the likelihood of selling fish, due to the fact that dams normally are used for other purposes besides fish farming and because dams have management more difficult, i.e., to the fish control and the amount of water.

"byprod" is a dummy variable that has value equal to 1 if the farmer uses by-products to fish feed. Among the investigated fish farmers all use manufactured fish feed, but only a few producers use products such as fruits, maize and cassava, in addition to supplementary feeding ration. As feed ration is the ideal and it is suitable for the cultivation of fish, the signal expected for this variable is negative.

"area" is a continuous variable that represents the total area of water, in hectares, in each property. Fish farmers with greater water area are more likely to be able to sell fish, because with more area to produce, the higher the chance of a good production.

\section{Data and Descriptive Analysis}

The data used for the proposed analysis in this article were collected through Project Divinópolis, research project from Embrapa Fisheries and Aquaculture that has been following the production of fish farmers in the Western of Tocantins state. Were conducted, in early 2012, interviews with 30 fish farmers, visiting them in their homes and applying a questionnaire that, among other technical questions of production, had questions of which were taken the variables used in the econometric model presented.

It is important to remember that these variables were collected before the actions of research and technology transfer proposed by this research project. This is because, most likely, after three years of guidance, training and development of new technologies and production processes, fish farmers will present different numbers, improving their indicators. Table 1 presents descriptive statistics of the variables collected at the beginning of the project and used in the logit model.

As can be seen in the first row of Table 1, the majority of fish farmers interviewed, corresponding to $70 \%$, reaches a quality in production so he can sell fish, which shows how the technological level of production and technical knowledge of the activity are

Table 1 Descriptive statistics of variables used in the logit model.

\begin{tabular}{llllll}
\hline Variable & Mean & \multicolumn{2}{l}{ Std. Dev. Min } & Max & $\begin{array}{l}\text { Expected } \\
\text { sign }\end{array}$ \\
\hline $\begin{array}{l}\text { Dependent } \\
(Z)\end{array}$ & 0.30 & 0.47 & 0 & 1 & N/A \\
exp & 2.59 & 1.91 & 0 & 7 & + \\
members & 2.57 & 1.81 & 1 & 9 & + \\
fem & 0.33 & 0.48 & 0 & 1 & + \\
transf & 0.47 & 0.51 & 0 & 1 & + \\
relig & 0.27 & 0.45 & 0 & 1 & $+/-$ \\
income & $2,228.79$ & $1,613.14$ & 100.00 & $7,500.00+/-$ \\
pond & 0.60 & 0.50 & 0 & 1 & + \\
byprod & 0.30 & 0.47 & 0 & 1 & - \\
area & 0.15 & 0.17 & 0.01 & 0.63 & + \\
\hline
\end{tabular}


below of desirable. The time of experience is, on average, about two and a half years in the activity which was expected because of public actions in region have been started recently. Regarding the number of people residing in the productive unit, the average was just over 2.5 members, although there is a considerable range in this variable, as we can see families with up to nine resident members.

In most farms, the woman does not participate in the production process, the household members are Catholic and do not receive any benefit transfer income from the government, although for the latter variable, almost half of households receive some kind of benefit. The monthly family income was above the national average, but this result may be explained by variable range, as there is a family with income of 7,500.00 reais, i.e., a very high standard for the Brazilian family farming. On the other hand, the lowest monthly family income was 100.00 reais, which shows that the social situation in the region can also be very difficult.

About variables most related with production, we can see that $60 \%$ of fish farmers use only ponds dug in production which may be a signal of potential of higher production capacity if they receive higher handling in the construction of ponds. With respect to fish feed, $70 \%$ uses only manufactured feed and 30\% also uses by-products of agriculture. The area of water also has a considerable range between fish farmers interviewed varying from 0.1 ha to 0.63 ha.

\section{Results}

With the methodology and data described in the previous sections, it were estimated the coefficients of Eq. (4) using the variables collected in individual interviews with farmers at the beginning of the Divinópolis Project. Thus, the coefficients were estimated by the method of maximum likelihood for the logit regression model presented. The results are presented in Table 2.

The results show that the probability of the fish
Table 2 Results for logit model.

\begin{tabular}{llllll}
\hline Variable & Coefficient & $\begin{array}{l}\text { Std. } \\
\text { error }\end{array}$ & $Z$ & $P>|\mathrm{Z}|$ & $\Delta$ Prob \\
\hline exp & 0.379 & 0.376 & 1.01 & 0.314 & 0.055 \\
members & -0.125 & 0.48 & -0.26 & 0.795 & -0.018 \\
fem & 1.836 & 1.735 & 1.06 & 0.29 & 0.316 \\
transf & $2.963^{*}$ & 1.773 & 1.67 & 0.095 & 0.458 \\
relig & -1.673 & 1.809 & -0.93 & 0.355 & -0.191 \\
income & 0.0004 & 0.0004 & 1.09 & 0.274 & 0.000 \\
pond & $3.568^{*}$ & 1.898 & 1.88 & 0.06 & 0.446 \\
byprod & -0.613 & 1.162 & -0.53 & 0.598 & -0.082 \\
area & $9.458^{*}$ & 4.902 & 1.93 & 0.054 & 1.368 \\
Log likelihood $=-13.832$ & & & \\
Pseudo $R^{2}=0.2452$ & & & & \\
$N=30$ & & & & & \\
\hline
\end{tabular}

*Significant at $10 \%$.

farmer sell fish is significantly and positively influenced by "transf", "pond" and "area" variables, i.e., farmers who receive some benefit from programs to transfer income from the government, who produces fish in pond dug or who have a large area of water are, on average, more likely to produce fish efficiently to sell their product. These results confirm the expected positive effect on the dependent variable of these three variables. All other variables were not significantly different from zero at a level of $10 \%$.

The likelihood of a fish farmer sells any quantity of fish increases by $45.8 \%$ if the household receives any benefit from the government, mainly BolsaFamília. This result shows the importance of government programs and can give an indication of which government policies should be explored to achieve improved the standard of living of small farmers.

Fish farmers who produce in ponds dug are more likely to sell fish $44.6 \%$ compared fish farmers who produce in dams. In regards to the water area, each additional hectare in the farm increases the likelihood of selling the product in $136.8 \%$. In additional for these information, it is important the recall that the average of size area of fish farms among respondents was about 0.15 ha. This result shows the importance of having a large area for growing fish.

It must be considered that the sample analyzed, although it is representative of all farmers in the 
region, presents a small number of individuals and, considering the large number of factors included as exogenous variables in the model, the few degrees of freedom of the estimated regression may have compromised the significance of the coefficient of some variables.

The result shows that these variables that had a significant effect on the endogenous variable had the expected signal effect. The result of variable "transf" confirms Brazilian research results that are finding positive social effects of the BolsaFamília program $[18,19]$. So this program that transfers money to extremely poor population, seems to be very useful for small fish farms, which is usually formed by enterprises that require low initial investment and have low cost of operation.

Fish farmers who produce in ponds dug also increase the likelihood of success of its production of fish, because this kind of pond is projected and constructed to facilitate the management of fish and allow better control of water quality. Paggi [20] have shown that this performance is technically better, but now we can see that for very small farmers, it has very important effect on the success of the business and it can determine if fish farming is feasible.

Furthermore, variables such as "byprod" and "members" which one would expect most significant result had no effect in the sample. It is known [21] that manufactured fish feed is very good for the fish growth, but for this sample of fish farmers who sell the fish in small local markets and do not have the need to sell high weight fish, this variable does not change the probability of sale and business success.

\section{Conclusions}

This article aimed to investigate which socioeconomic factors have an influence on the fact of fish farmers in the region of the Divinópolis in Tocantins state reach a level of efficiency in production enough that the fish can be good for sale in the local market. Then, we used data from Divinópolis
Project, which is being run by Embrapa Fisheries and Aquaculture. These data were collected at the beginning of the project, in the year 2012 and correspond to the reality of the fish farmers before the actions of research and training that the project began performing in the same year.

In 2012 , only $30 \%$ of the fish farmers could at some point sell the fish produces, and the others had only household consumption as the end of production of fish. In a total of nine exogenous factors evaluated, three had significant effect on the probability of sale of fish produced on the household farm. Farmers that receive some benefit from income transfer programs of the government, that produces fish in pond dug or that have large area of water have, on average, more likelihood to produce fish efficiently to get sell your output.

One of these indicatives is that the payment of income transfer programs, which economic literature has been showing a lot of benefits, has a positive influence on the production of small farmers and thus the program helps not only the basic needs of the beneficiary but also becoming more productive.

Considering technical factors such as the area of water and production in ponds, government actions can have good efficiency if it was made technical trainings with farmers, both for the management of fish and to perform initial investment in production, for example, how to make ponds dug, equipment purchase, preparation of farm to maximize production, etc..

These results are important because significant effect variables already had its technical importance in production at different levels and sizes of farms, but now we could see that for small farms these factors are important in determining the success of the sale of fish and it can influence the feasibility of business.

It is important that more research be done with small fish farming and also analyzes other places of the world because fish farming and additional income are very important for farmers who live on a very low 
income level. Here we only indicated the importance of some variables in a successful production, but is still necessary to investigate these factors in larger volume producers and fish farmers with different socioeconomic characteristics.

Many of these actions have been undertaken by the Divinópolis Project with fish farmers in the region of this study and it is expected that after the trainings conducted and technologies developed for this population, the quality of fish production improves and thus fish farmers are able to sell more fish, not only getting improvements in food security, but also in profit of the small farm. The results found in this study and in future by Divinópolis Project may be multiplied to other regions of Brazil and the world that have similar background and the same technical and socio-economic needs.

\section{References}

[1] Brazilian Institute of Geography and Statistics, Brute intern product of the cities 2004-2008 [Online], http://www.ibge.gov.br/home/estatistica/economia/pibmu nicipios/2004_2008/tabelas_pdf/tab01.pdf (accessed Apr. 13, 2010). (in Portuguese)

[2] PNUD, Ranking of the Development Human Index of the States in 2005 [Online], 2008, http://www.pnud.org.br/pobreza_desigualdade/reportagen s/index.php?id01=3039\&lay=pde (accessed Apr. 10, 2010). (in Portuguese)

[3] Brazilian Institute of Geography and Statistics, Research about Budget Familiar (POF) 2008-2009 [Online], http://www.ibge.gov.br/home/estatistica/indicadores/sipd/ sexto_forum/POF.pdf (accessed Apr. 13, 2010). (in Portuguese)

[4] Brazilian Institute of Geography and Statistics, Panel of Cities

[Online], http://www.ibge.gov.br/cidadesat/painel/painel.php?codm un=170025\# (accessed Apr. 13, 2010). (in Portuguese)

[5] Brazilian Institute of Geography and Statistics, National Research by Household Sample, Food Safety 2004, Ministry of Planning, Budget and Management Brazilian Institute of Geography and Statistics [Online], p. 140, http://www.ibge.gov.br/home/estatistica/populacao/trabal hoerendimento/pnad2004/suplalimentar2004/default.sht (accessed Apr. 13, 2010). (in Portuguese)

[6] A.A. Simão, Diversification as an alternative for the development of family farming South Mineira, Master
Dissertation, Federal University of Lavras, Lavras, MG, 2005, p. 149. (in Portuguese)

[7] M.S. Edínia, A.K.P. Borges, Socioeconomic study of fairs family farming in the state of Tocantins [Online], 2011, Rural Development Institute of Tocantins State, http://ruraltins.to.gov.br (accessed Apr. 6, 2011). (in Portuguese)

[8] E. Ono, F. Kubitza, Family psi culture as a tool for development and food security in rural areas, Review of Aquiculture Panorama 20 (117) (2010) 1-10.

[9] J.F. Muir, C.G. Nugent, Aquaculture production trends: Perspectives for food security, in: Kyoto Conference Outcome \& Papers Presented, FAO Fisheries Department, Rome, 1995.

[10] A.E. Baccarin, A.F.G. Leonardo, L. Tachibana, C.F. Correia, Psiculturein community quilombo remnant: A case of study, Economic Information 39 (11) (2009) 42-47. (in Portuguese)

[11] W.C. Valenti, Sustainable aquaculture, in: Zootechny Congress, Portuguese Association of Zootechny Engineers, Vila Real, Portugal, 2002, pp. 111-118. (in Portuguese)

[12] O.J. Sabbag, R.R. Rozales, M.A.A. Tarsitano, A.N. Silveira, Economic analysis of tilapia production in a model of associative property in Ilha Solteira, São Paulo, Brazil, Costs and Agribusiness 13 (2) (2007). (in Portuguese)

[13] J. Antle, R. Valdivia, Methods for assessing economic, environmental and social impacts of aquaculture technologies: Adoption of integrated agriculture-aquaculture in Malawi, Thesis, Oregon State University, 2011.

[14] R.H. Caffey, R.F. Kazmierczak, Factors influencing technology adoption in a Louisiana aquaculture system, J. Agr. and Applied Econ. 26 (1) (1994) 264-274.

[15] E.C. Musaba, M. Namukwambi, Socio-economic determinants of consumer fish purchase in Windhoek, Namibia, African Journal of Agricultural Research 6 (6) (2011) 1483-1488.

[16] T. Amemiya, Qualitative response models: A survey, J. Econ. Lit. 19 (1981) 1483-1536.

[17] O. Capps, R.A. Kramer, Analysis of food stamp participation using qualitative choice models, Am. Journal Agric. Econ. 67 (1985) 49-59.

[18] S. Soares, P.H.G.F. de Souza, R.G. Osório, F.G. Silveira, The impacts of the benefit from the exchange family program on inequality and poverty, Exchange Family 2 (2010) 527-529. (in Portuguese)

[19] G.B. Duarte, B. Sampaio, Y. Sampaio, Exchange family program: Impact of the transfers of expenses with food on rural families, Journal of Economics and Rural Sociology 47 (4) (2009) 903-918. (in Portuguese) 
Farmers in Tocantins State, Brazil

[20] L.C. Paggi, Limnological evaluation in a fish-farming system on Paranaíta area, Doctoral Dissertation, Paulista State University, Brazil, 2006. (in Portuguese)
[21] F. Kubitza, Nutrition and feeding of tilapias-Part I, Aquaculture Panorama 2 (52) (1999) 42-50. (in Portuguese) 